УДК 378.147.31-378.147.34

DOI 10.23951/2307-6127-2020-2-30-34

\title{
МАГИСТР В ШКОЛЕ: БЫТЬ ИЛИ НЕ БЫТЬ
}

\section{Л. А. Никитина}

\section{Алтайский государственньй педагогический университет, Барнаул}

Рассматривается вопрос о положении магистров в школе и позиции руководителей общеобразовательных школ по отношению к магистерской подготовке. На основе изучения вопросов, связанных с затруднениями в процессе обучения в магистратуре, установлено, что в школе не создаются условия для успешного обучения, поскольку руководители не проявляют заинтересованности именно в магистерской подготовке педагога. По результатам анкетирования руководителей общеобразовательных школ установлено, что работодатели не видят принципиальной значимости в многоуровневой подготовке педагога, поскольку нормативно не закреплены функции и виды деятельности магистров в школе. При этом директора школ готовы создавать условия для обучения педагогов в магистратуре, привлекать к исследовательской и проектно-управленческой деятельности, к педагогическому сопровождению работы по совершенствованию деятельности педагогов школы, включать их в состав команды по управлению в школе. Обозначена проблема набора с точки зрения распределения контрольных цифр приема в магистратуру, обусловленная отсутствием заинтересованности работодателей в магистерской подготовке педагога.

Ключевые слова: двухуровневая подготовка, бакалавр, магистр, педагог, стандарт, высшее образование, функиии и виды деятельностей.

Двухуровневая подготовка педагогов, включающая бакалавриат и магистратуру, на сегодняшний день законодательно закреплена федеральными государственными образовательными стандартами высшего образования (ФГОС ВО 3+, ФГОС ВО 3 ++), а также профессиональным стандартом «Педагог» $[1,2]$. Реализации уровневой подготовки на практике посвящены работы, связанные с изучением роли магистратуры в профессиональном образовании (Т. И. Байденко), с конкретизацией содержания и результатов магистерской подготовки (Е. Н. Никулина), различий бакалаврских и магистерских программ (Т. И. Сергеева) [3-5]. Особо рассматриваются вопросы выбора направлений и методологических оснований в создании основных образовательных программ, психолого-педагогического сопровождения технологий обучения в магистратуре, выстраивание оснований для измерения результатов обучения в вузе, необходимость смены в магистратуре моделей организации совместной деятельности и типа коммуникации преподавателя и студентов (Е. А. Галкина, С. И. Поздеева, Л. Г. Смышляева) [6-8]. Все это позволяет сделать вывод о том, что преподаватели высшей школы не только приняли двухуровневую систему подготовки педагога, но и изучают проблемы в организации магистерской подготовки, разрабатывают, внедряют новые образовательные программы и технологии.

Однако практика осуществления в вузе магистерской подготовки обозначила ряд проблем, которые напрямую связаны с положением выпускника магистратуры в школе. Так, проведенный нами опрос обучающихся в магистратуре показал, что 56 \% респондентов (учителей начальной школы) отмечают в качестве трудностей в процессе обучения в вузе 
«незаинтересованность руководителей организации» ${ }^{1}$ в том, что они получают степень магистра педагогики.

В связи с этим обстоятельством мы решили изучить мнение руководителей образовательных организаций, которые выступают работодателями. В опросе приняли участие 406 директоров школ Алтайского края². Нами был разработана анкета, которая включала вопросы, касающиеся выявления предпочтений руководителей при приеме на работу, готовности взаимодействовать с магистрами в процессе их обучения и после окончания магистратуры, участия выпускника магистратуры в образовательной деятельности в школе (табл. 1).

Таблица 1 Результаты анкетирования руководителей общеобразовательных школ Алтайского края

\begin{tabular}{|c|c|c|c|}
\hline Вопрос & Вариант ответа & $\begin{array}{l}\text { Кол-во } \\
\text { ответов }\end{array}$ & $\begin{array}{c}\% \text { от } \\
\text { общего } \\
\text { кол-ва } \\
\text { ответов }\end{array}$ \\
\hline \multirow{5}{*}{$\begin{array}{l}\text { При приеме на работу } \\
\text { Вы отдадите предпоч- } \\
\text { тение: }\end{array}$} & - бакалавру образования & 15 & 3 \\
\hline & - магистру образования & 58 & 14 \\
\hline & - с высшим образованием (не обязательно педагогическим) & 10 & 2 \\
\hline & - со средним специальным образованием & 0 & 0 \\
\hline & - с педагогическим образованием & 323 & 80 \\
\hline \multirow{4}{*}{$\begin{array}{l}\text { Педагог решил } \\
\text { получить магистер- } \\
\text { скую подготовку, Вы: }\end{array}$} & - создадите ему условия для обучения в магистратуре & 344 & 84 \\
\hline & - посоветуете заниматься самообразованием & 13 & 3 \\
\hline & - выясните, зачем она ему нужна & 31 & 8 \\
\hline & $\begin{array}{l}\text { - сам захотел, пусть сам и организует свою учебу, только } \\
\text { обязательно выполняет все функции педагога }\end{array}$ & 36 & 4 \\
\hline \multirow{5}{*}{$\begin{array}{l}\text { В школе работает } \\
\text { магистр образования, } \\
\text { Вы: }\end{array}$} & $\begin{array}{l}\text { - привлечете его к организации исследовательской деятель- } \\
\text { ности педагогов }\end{array}$ & 116 & 28 \\
\hline & $\begin{array}{l}\text { - поручите ему осуществлять педагогическое сопровожде- } \\
\text { ние совершенствования деятельности педагогов (участие в } \\
\text { конкурсах, методических семинарах и пр.) }\end{array}$ & 194 & 47 \\
\hline & - включите его в команду руководящего состава школы & 38 & 9 \\
\hline & - переведете на новый уровень квалификации & 14 & 3 \\
\hline & - оставите все без изменений & 44 & 11 \\
\hline \multirow{4}{*}{$\begin{array}{l}\text { Для Вас принципиаль- } \\
\text { но выделение двух } \\
\text { уровней в подготовке } \\
\text { педагога (бакалавра, } \\
\text { магистра): }\end{array}$} & - да & 35 & 7 \\
\hline & - нет & 320 & 79 \\
\hline & - не вижу смысла & 46 & 11 \\
\hline & - лишняя «головная боль» при приеме на работу & 5 & 1 \\
\hline
\end{tabular}

Анализ ответов позволяет зафиксировать противоречивую ситуацию:

Так, основная часть респондентов (80\%) при приеме на работу в школу ориентируются на наличие у претендента педагогического образования, не дифференцируя уровень его подготовки (среднее специальное образование, бакалавриат, магистратура). И это понятно, поскольку школе нужен педагог, который умеет решать профессиональные задачи в обучении, воспитании и развитии. Только $14 \%$ из числа опрошенных указали на возможность приема на работу магистров. Хотя, как показывает практика трудоустройства выпускников педагогического вуза, именно педагоги, обучавшиеся по программе бакалавриата, приходят на работу в школу в первую очередь.

\footnotetext{
${ }^{1}$ Опрос проводился с обучающимися по магистерской программе «Управление развитием качества начального образования» (заочной и очной формы). В опросе приняли участие 24 человека, из них 14 учителей начальной школы, 6 работников дошкольных учреждений, 4 работника непедагогической сферы.

${ }^{2}$ Анкетирование было проведено при поддержке Министерства образования и науки Алтайского края в январе 2020 г.
} 
Отвечая на вопрос «Педагог решил получить магистерскую подготовку, Вы...», руководители решительно заявляют о том, что они готовы «создать ему условия для обучения в магистратуре» (84 \% из числа опрошенных). Это позволяет предположить, что школы ждут магистров. При этом 15 \% респондентов настороженно относятся к возможности обучения педагогов в магистратуре («выясните, зачем она ему нужна» - 8 \%, «сам захотел, пусть сам и организует свою учебу, только обязательно выполняет все функции педагога» - 4 \%, «посоветуете заниматься самообразованием»- 3 \%).

Использование потенциала образовательной подготовки магистра директора, отвечая на прогностический вопрос «В школе работает магистр образования, Вы...», видят в том, что «поручат ему осуществлять педагогическое сопровождение совершенствования деятельности педагогов (участие в конкурсах, методических семинарах и пр.)»- 47 \%; «привлекут его к организации исследовательской деятельности педагогов» - 28 \%; «включат его в команду руководящегго состава школьл» - 9 \%. При этом 11 \% «оставят все без изменений», а $3 \%$ - «переведут на новый уровень квалификации». Данные результаты свидетельствуют о видении большинством руководителей школ возможностей выполнения магистрами исследовательской и управленческой деятельности в школе.

При вроде бы положительном мнении о месте магистра в школе, руководители школ, отвечая на вопрос «Для Вас принципиально выделение двух уровней в подготовке педагога (бакалавра, магистра)», 79 \% выбрали вариант ответа «нет» («не вижу смысла» - 11 \%, «лишняя „головная боль“ “при приеме на работу» - 1 \%), и только 7 \% считают целесообразной двухуровневую подготовку педагога.

Такое разноплановое отношение к магистерской подготовке, на наш взгляд, обусловлено тем, что не определена и нормативно не закреплена функция магистра в школе и не обозначены виды деятельности, которые он может выполнять. При этом отметим, что профессиональный стандарт педагога дошкольного, начального, основного и среднего общего образования определяет трудовые функции, которые соответствуют 6-му уровню квалификации (бакалавру), а специфика профессиональной педагогической деятельности специалиста 7-го уровня квалификации (магистра) не представлена [2]. В связи с этим работодатели затрудняются как в предъявлении дифференцированных требований к бакалаврам и магистрам, так и в привлечении магистров к преобразованию школьной практики.

Такая ситуация с положением магистров в школе приводит к тому, что при определении контрольных цифр приема (КЦП) с учетом запросов работодателей, актуальным остается набор на бакалаврскую программу подготовки педагога (табл. 2).

Таблица 2

Распределение контрольных ичифр приема по направлению «Педагогическое образование» в Алтайском государственном педагогическом университете

\begin{tabular}{|c|c|c|c|c|c|}
\hline \multirow{2}{*}{ Год поступления } & Общее кол-во & \multicolumn{2}{|c|}{ Бакалавриат } & \multicolumn{2}{|c|}{ Магистратура } \\
\cline { 3 - 6 } & абитуриентов & Кол-во мест & $\%$ от общ. & Кол-во мест & \% от общ. \\
\hline 2017 & 998 & 697 & 69 & 301 & 30 \\
\hline 2018 & 1025 & 678 & 66 & 347 & 33 \\
\hline 2019 & 742 & 589 & 79 & 153 & 20 \\
\hline
\end{tabular}

Примечание. Данные контрольных цифр приемы взяты с сайта https://pricom.altspu.ru/statistika-proshlykh-let/ (дата обращения: 20.01.2020).

Анализ контрольных цифр приема в Алтайский государственный педагогический университет за последние три года (2017-2019) показывает, что по направлению «Педагогическое образование» набор на программу бакалавриата составляет от 66 до 79 \% от общего количества выделенных бюджетных мест, тогда как на программу магистратуры - от 20 до 
33 \%. Получается, что магистерская подготовка не актуальна для заказчиков (в частности, в области педагогического образования).

Изучение положения магистров в школе во время учебы и после вновь поднимает вопрос о согласованности не только стандартов, но и требований к педагогу при приеме в школу с учетом его уровня подготовки, поскольку они могут решать задачи профессиональной деятельности разных типов: педагогической, проектной, методической, научноисследовательской, организационно-управленческой и др. Но эти возможности остаются не востребованными, тогда как приобретенный выпускниками магистратуры образовательный потенциал позволит совершенствовать практику школы.

\section{Список литературы}

1. Приказ Минобрнауки России от 22.02.2018 № 126 «Об утверждении федерального государственного образовательного стандарта высшего образования - магистратура по направлению подготовки 44.04.01 „Педагогическое образование“” (Зарегистрировано в Минюсте России 15.03.2018 № 50361). URL: http://fgosvo. ru/fgosvo/152/150/25/117 (дата обращения: 16.01.2020).

2. Приказ Минтруда России от 18.10.2013 № 544н (с изм. от 25.12.2014) «Об утверждении профессионального стандарта „Педагог (педагогическая деятельность в сфере дошкольного, начального общего, основного общего, среднего общего образования) (воспитатель, учитель)“». URL: http://fgosvo.ru/uploadfi les/profstandart/01.001 . pdf (дата обращения: 15.01.2020).

3. Байденко В. И., Селезнева Н. А. Конкурентноспособные образовательные программы: к формированию концепции // Высшее образование сегодня. 2011. № 5. С. 24-29.

4. Никулина Е. Г. Изменения в содержании профессиональной подготовки в магистратуре педагогического вуза: дис. ... канд. пед. наук. Омск, 2015.

5. Сергеева Т. И., Винокурова Т. С., Татаринова В. А. Обучение в магистратуре как фактор личностного и профессионального развития педагога // Научно-методический электронный журнал «Концепт». 2015. Т. 26. C. 491-495. URL: http://e-koncept.ru/2015/95383.htm

6. Галкина Е. А., Макарова О. Б., Марина А. В., Иашвили М. В. Организационно-педагогические требования к программам магистратуры в условиях введения профессионального стандарта педагога и модернизации педагогического образования // Вестник педагогических инноваций. 2017. № 4 (48). С. 35-50.

7. Поздеева С. И. Магистратура как пространство профессионально-личностного развития студента и преподавателя // Высшее образование в России. 2018. № 3. С. 144-151.

8. Смышляева Л. Г., Нерадовская О. Р., Матвеев Д. М., Смышляев А. В. Образовательный потенциал интеграции неформального образования и практик магистерской подготовки // Научно-педагогическое обозрение (Pedagogical Review). 2019. Вып. 6 (28). С. 122-132

Никитина Любовь Андреевна, доктор педагогических наук, доцент, заведующая кафедрой теории и методики начального образования, Алтайский государственный педагогический университет (ул. Молодежная, 55, Барнаул, Россия, 656031). E-mail: nikitina.fnk@rambler.ru

Материал поступил в редакиию 27.01.2020.

DOI 10.23951/2307-6127-2020-2-30-34

\section{MASTER IN SCHOOL: TO BE OR NOT TO BE}

\section{A. Nikitina}

Altai State Pedagogical University, Barnaul, Russian Federation

In this article, the author considers the issue of the position of masters in school and the position of the heads of secondary schools for master's training. Based on the study of difficulties in the process of studying at a magistracy, the author found that the school does 
not create conditions for successful learning, because the leaders do not show interest in the master's training of a teacher. Based on the results of a survey of the heads of secondary schools, the researcher concludes that employers do not see fundamental importance in the multi-level training of the teacher, since the functions and types of activities of masters in the school are not legally fixed. At the same time, school principals are ready to create conditions for the training of teachers in the magistracy, to involve in research and design and management activities, in pedagogical support of work to improve the activities of school teachers, to include them in the school management team. The author outlines the problem of recruitment from the point of view of the distribution of master figures for admission to the magistracy, which is caused by the lack of interest of employers in the master's training of the teacher.

Keywords: two-level training, bachelor, master, teacher, standard, higher education, functions and activities.

\section{References}

1. Prikaz Minobrnauki Rossii ot 22.02.2018 N 126 “Ob utverzhdenii federal'nogo gosudarstvennogo obrazovatel'nogo standarta vysshego obrazovaniya - magistratura po napravleniyu podgotovki 44.04 .01 "Pedagogicheskoye obrazovaniye" (Zaregistrirovano v Minyuste Rossii 15.03.2018 N 50361) [Order of the Ministry of Education and Science of Russia dated 22.02.2018, no. 126 "On approval of the federal state educational standard of higher education - master's program in the direction of preparation 44.04.01 Pedagogical education" (Registered in the Ministry of Justice of Russia on March 15, 2018 no. 50361)] (in Russian). URL: http://fgosvo.ru/fgosvo/152/150/25/117 (accessed 16 January 2020)

2. Prikaz Mintruda Rossii ot 18.10.2013 N 544n (s izm. ot 25.12.2014) «Ob utverzhdenii professional'nogo standarta "Pedagog (pedagogicheskaya deyatel'nost'v sfere doshkol'nogo, nachal'nogo obshchego, osnovnogo obshchego, srednego obshchego obrazovaniya) (vospitatel', uchitel') ' [Order of the Ministry of Labor of Russia dated 18 October 2013 N 544n (as amended on 25 December 2014) "On approval of the professional standard "Teacher (pedagogical activity in the field of preschool, primary general, basic general, secondary general education) (educator, teacher)"] (in Russian). URL: http://fgosvo.ru/uploadfi les/profstandart/01.001.pdf (accessed 15 January 2020).

3. Baydenko V. I., Selezneva N. A. Konkurentnosposobnye obrazovatel'nye programmy: k formirovaniyu kontseptsii [Competitive educational programs: towards conceptualization]. Vyssheye obrazovaniye segodnya, 2011, no. 5, pp. 24-29 (in Russian).

4. Nikulina E. G. Izmeneniya v soderzhanii professional'noy podgotovki v magistrature pedagogicheskogo vuza. Dis.... kand. ped. nauk [Changes in the content of vocational training in the master's program of a pedagogical university. Diss. cand. of ped. sci.]. Omsk, 2015. 340 p. (in Russian).

5. Sergeyeva T. I., Vinokurova T. S., Tatarinova V. A. Obucheniye v magistrature kak faktor lichnostnogo i professional'nogo razvitiya pedagoga [Teaching in the magistracy as a factor in the personal and professional development of a teacher]. Nauchnometodicheskiy elektronnyy zhurnal "Kontsept", 2015, vol. 26, pp. 491-495 (in Russian). URL: http://e-koncept.ru/2015/95383.htm (accessed 17 January 2020).

6. Galkina Ye. A., Makarova O. B., Marina A. V., Iashvili M. V. Organizatsionno-pedagogicheskiye trebovaniya k programmam magistratury $\mathrm{v}$ usloviyakh vvedeniya professional'nogo standarta pedagoga i modernizatsii pedagogicheskogo obrazovaniya [Organizational and pedagogical requirements for master's programs in the context of the introduction of a professional standard for teachers and the modernization of teacher education]. Vestnik pedagogicheskikh innovatsiy - Bulletin of pedagogical innovation, 2017, no. 4 (48), pp. 35-50 (in Russian).

7. Pozdeyeva S. I. Magistratura kak prostranstvo professional'no-lichnostnogo razvitiya studenta i prepodavatelya [Master's degree environment as a space for personal professional development of students and professors]. Vyssheye obrazovaniye v Rossii - Higher Education in Russia, 2018, no. 3, pp. 144-151 (in Russian).

8. Smyshlyayeva L.G., Neradovskaya O.R., Matveyev D.M., Smyshlyayev A.V. Obrazovatel'nyy potentsial integratsii neformal'nogo obrazovaniya i praktik magisterskoy podgotovki [Educational potential of the integration of nonformal education and the practice of master training]. Nauchno-pedagogicheskoye obozreniye - Pedagogical Review, 2019, vol. 6 (28), pp. 122-132 (in Russian).

Nikitina L.A., Altai State Pedagogical University (ul. Molodezhnaya, 55, Barnaul, Russian Federation, 656031). E-mail: nikitina.fnk@rambler.ru 